
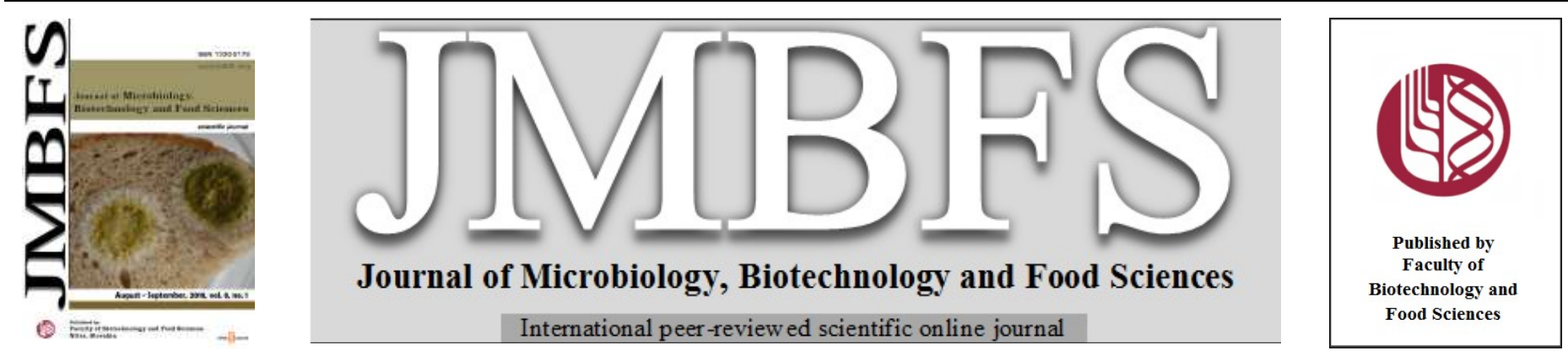

\title{
ANTIFUNGAL EFFECT OF A BACTERIOCIN OF BACILLUS METHYLOTROPHICUS BM47 AND ITS POTENTIAL APPLICATION AS A BIOPRESERVATIVE IN TRADITIONAL BULGARIAN YOGURT
}

\author{
Yulian Tumbarski*l, Velichka Yanakieva ${ }^{1}$, Radosveta Nikolova ${ }^{1}$, Gergana Mineva ${ }^{1}$, Ivelina Deseva ${ }^{2}$, Dasha Mihaylova ${ }^{3}$ and Ivan \\ Ivanov ${ }^{4}$
}

\author{
Address(es): Yulian Tumbarski, DVM, PhD \\ ${ }^{1}$ Department of Microbiology, University of Food Technologies, 26, Maritsa Blvd., 4002 Plovdiv, Bulgaria. \\ ${ }^{2}$ Department of Analytical Chemistry and Physicochemistry, University of Food Technologies, 26, Maritsa Blvd., 4002 Plovdiv, Bulgaria. \\ ${ }^{3}$ Department of Biotechnology, University of Food Technologies, 26, Maritsa Blvd., 4002 Plovdiv, Bulgaria. \\ ${ }^{4}$ Department of Organic Chemistry and Inorganic Chemistry, University of Food Technologies, 26, Maritsa Blvd., 4002 Plovdiv, Bulgaria.
}

*Corresponding author: tumbarski@abv.bg

doi: 10.15414/jmbfs.2018.8.1.659-662

\section{ARTICLE INFO}

Received 7. 5. 2018

Revised 5. 6. 2018

Accepted 11. 6. 2018

Published 1. 8. 2018

Regular article OPEN $\partial_{\text {ACCESS }}$

\begin{abstract}
Bacteriocins are biologically active compounds of proteinaceous nature synthesized by a large number of microorganisms, including members of bacterial genus Bacillus and lactic acid bacteria (LAB). The broad antimicrobial spectrum of bacteriocins against various spoilage and pathogenic microorganisms stimulated the research efforts for their investigation and potential application in different branches of food industry as natural preservatives. The promising antimicrobial activity of bacteriocins makes them suitable for application as biopreservatives and alternatives of chemical preservatives in dairy industry for production of fermented or non-fermented milk products. Therefore, the aim of the present study was to evaluate the antifungal effect of a bacteriocin isolated from Bacillus methylotrophicus strain BM47 and the possibilities for its application as a potential biopreservative of traditional Bulgarian yogurt. The results demonstrated that the addition of a purified bacteriocin in dose of $1 \mathrm{AU} / \mathrm{mL}$ of milk led to significant reduction of the fungal spores and mycelial growth of the indicator microorganism Penicillium sp. in the yogurt, without a change of its organoleptic properties, and biochemical and microbiological parameters during the 4-week period of storage.
\end{abstract}

Keywords: Bulgarian yogurt, bacteriocins, Bacillus methylotrophicus, food biopreservation

\section{INTRODUCTION}

Yogurt (or yoghurt) is one of the most famous and widely spread traditional dairy products in Bulgaria, produced by bacterial fermentation of cow's, buffalo's, sheep's and goat's milk. Yogurt is known on the Balkans since ancient times, when the Thracians have obtained it from self-fermented sheep's milk. Nowadays, it takes an important role in the diet of the Bulgarians due to its excellent nutritional characteristics and beneficial effects on human health. Besides the rich chemical composition, including all natural nutritional constituents and significant amounts of calcium in a bioavailable form, yogurt possesses many therapeutic effects on lactose intolerance and some gastrointestinal disorders such as diarrhea, inflammatory bowel disease (IBD) and irritable bowel syndrome (IBS), and weight control (McKinley, 2005). Bulgarian yogurt it is often recommended as food for improving of the metabolism, reducing of the cholesterol and even as an anticarcinogenic agent (Fikiin et al., 1997). Many recent studies have demonstrated that yogurt exhibits positive effects on the gut microbiota and is associated with a reduced risk for gastrointestinal diseases, cardiovascular diseases, type 2 diabetes, allergies, respiratory diseases, pregnancy outcomes, as well as for improving of dental and bone health (Fisberg and Machado, 2015).

The traditional Bulgarian yogurt, known also as "kiselo mlyako", is a coagulated milk product, characterized by smooth texture, thick consistency and pleasant sour flavor. The uniqueness of Bulgarian yogurt is famous worldwide and it is attributed to the country's microclimate and the specific fermentation by symbiotic cultures of Lactobacillus delbrueckii subsp. bulgaricus and Streptococcus salivarius subsp. thermophilus (Tropcheva et al., 2014a). These starter bacteria are known to produce a wide spectrum of volatile organic aroma compounds such as acetaldehyde, diacetyl, volatile fatty acids that determine the specific flavour of Bulgarian yogurt (Beshkova et al., 1998). Another compound, produced by the starter microorganisms, which imparts the distinctive flavour of yogurt and its related products, is the lactic acid. Lactic acid is a major end product during the fermentation of carbohydrates by the lactic acid bacteria (LAB). The rapid fermentation process leads to improving of the organoleptic qualities of milk- and non-milk products, and also extends their shelf life by inhibition of saprophytic and pathogenic microorganisms (Cholakov et al., 2017).

Although significant antimicrobial activity of the lactic acid produced at high amounts during the milk fermentation and suppressive effect of the low $\mathrm{pH}$, numerous studies revealed the occurrence of foodborne pathogens, which may survive the pasteurization or to enter the pasteurized milk via contamination or experimental inoculation. The different pathogens can survive in yogurt for a various period of time, which for Listeria monocytogenes is limited between 9 and $15 \mathrm{~h}$ (Schaack and Marth, 1988) to $>6$ days (Ikonomov and Todorov, 1967); up to $16 \mathrm{~h}$ for Escherichia coli $\mathrm{O} 157: \mathrm{H} 7$ of storage at $4-22^{\circ} \mathrm{C}$ (Bachrouri et al., 2002); from 2 to 4 days for Brucella spp. (Falenski et al., 2010); more than one week of storage at $5^{\circ} \mathrm{C}$ for Yersinia enterocolitica (Ahmed et al., 1986); between 2 days at $4^{\circ} \mathrm{C}$ (Pazakova et al., 1997) and 10 days of storage at room temperature $\left(22^{\circ} \mathrm{C}\right)$ for Staphylococcus aureus (Benkerroum et al., 2002); over 43 days of storage at temperatures between 4 and $25^{\circ} \mathrm{C}$ for Salmonella enterica serovar typhimurium (Álvarez-Ordóñez et al., 2013).

The raw milk for production of yogurt is often a vector for spoilage and toxigenic microorganisms such as yeasts and fungi, which is serious problem nowadays due to the resistance of fungal spores to exposure of high temperature and low $\mathrm{pH}$. The most commonly detected fungi in raw milk belong to the genera Penicillium, Geotrichum, Aspergillus, Mucor and Fusarium (Quigley et al., 2013) that renders the milk unsuitable either for direct consumption or for subsequent processing. In addition, it is estimated that between 5 and $10 \%$ of the world's food production is lost due to spoilage caused by fungal contamination (Pitt and Hocking, 2009).

Therefore, the aim of the present study was to determine the antifungal activity against Penicillium sp. of a bacteriocin isolated from Bacillus methylotrophicus BM47 and to evaluate the possibilities for its application as a potential biopreservative of traditional Bulgarian yogurt. 


\section{MATERIAL AND METHODS}

\section{Materials}

\section{Bacteriocin}

Purified by fast protein liquid chromatography (FPLC) and lyophilized substance containing a protein of intermediate molecular size (19578 Da) was used. This bacteriocin was synthesized by Bacillus methylotrophicus strain BM47, isolated from natural thermal spring water in Haskovo region, Bulgaria.

\section{Indicator microorganism}

The fungus Penicillium sp. (our isolate) from the collection of the Department of Microbiology at University of Food Technologies, Plovdiv, Bulgaria, was selected as indicator microorganism.

\section{Culture media}

Malt extract agar (MEA)

This medium was used for cultivation of the test fungus. MEA was prepared by the following prescription: $20 \mathrm{~g}$ malt extract, $20 \mathrm{~g}$ dextrose, $6 \mathrm{~g}$ peptone and $15 \mathrm{~g}$ agar dissolved in $1 \mathrm{~L}$ of deionized water. The final $\mathrm{pH}$ was corrected to 5.5 and the medium was sterilized by autoclaving at $121^{\circ} \mathrm{C}$ for $15 \mathrm{~min}$

\section{Luria-Bertani glucose agar ( $L B G$ )}

This medium was used for determination of MIC. LBG-agar was prepared by the following prescription: $10 \mathrm{~g}$ tryptone, $5 \mathrm{~g}$ yeast extract, $10 \mathrm{~g} \mathrm{NaCl}, 10 \mathrm{~g}$ glucose and $15 \mathrm{~g}$ agar dissolved in $1 \mathrm{~L}$ of deionized water. The final $\mathrm{pH}$ was adjusted to 7.5 and the medium was autoclaved at $121^{\circ} \mathrm{C}$ for $20 \mathrm{~min}$.

\section{Chloramphenicol glucose agar (CGA)}

CGA is a selective medium for enumeration of yeasts and fungi, prepared according to the manufacturer's (Scharlab S.L., Spain) prescription: $20 \mathrm{~g}$ dextrose $5 \mathrm{~g}$ yeast extract, $0.1 \mathrm{~g}$ chloramphenicol and $15 \mathrm{~g}$ agar dissolved in $1 \mathrm{~L}$ of deionized water. The final $\mathrm{pH}$ was corrected to 6.6 and the medium was sterilized in autoclave at $121^{\circ} \mathrm{C}$ for $15 \mathrm{~min}$

\section{Man, Rogosa and Sharpe agar (MRS)}

MRS-agar is a selective medium for cultivation and enumeration of lactobacilli, prepared according to the manufacturer's (Merck, Germany) prescription: peptone proteose $10 \mathrm{~g}$, meat extract $8 \mathrm{~g}$, yeast extract $4 \mathrm{~g}, \mathrm{D}(+)$-glucose $20 \mathrm{~g}$, sodium acetate $5 \mathrm{~g}$, triammonium citrate $2 \mathrm{~g}$, magnesium sulfate $0.2 \mathrm{~g}$, manganese sulfate $0.05 \mathrm{~g}$, dipotassium phosphate $2 \mathrm{~g}$, polysorbate $80-1 \mathrm{~g}$ and agar $14 \mathrm{~g}$ dissolved in $1 \mathrm{~L}$ of deionized water. The final $\mathrm{pH}$ was corrected to 6.2 and the medium was autoclaved at $121^{\circ} \mathrm{C}$ for $15 \mathrm{~min}$

M17 agar

M17-agar is a selective medium for cultivation and enumeration of lactic streptococci, prepared according to the manufacturer's (Merck, Germany) prescription: casein enzymic hydrolysate $2.5 \mathrm{~g}$, peptic digest of animal tissue 2.5 $\mathrm{g}$, papaic digest of soyaben meal $5 \mathrm{~g}$, yeast extract $2.5 \mathrm{~g}$, beef extract $5 \mathrm{~g}$, ascorbic acid $0.5 \mathrm{~g}$, magnesium sulphate $0.25 \mathrm{~g}$, lactose $5 \mathrm{~g}$, disodium- $\beta$-glycerophosphate $19 \mathrm{~g}$ and agar $10 \mathrm{~g}$. The final $\mathrm{pH}$ was adjusted to 7.1 and the medium was sterilized by autoclaving at $121^{\circ} \mathrm{C}$ for $15 \mathrm{~min}$.

\section{Starter culture}

Symbiotic starter culture MZ2, containing Lactobacillus delbrueckii subsp bulgaricus LBG MZ (NBIMCC 3600) and Streptococcus salivarius subsp. thermophilus 35 (NBIMCC 3597) in ratio 1:2 was used. The starter culture MZ2 was kindly provided by Prof. Zapryana Denkova from the Department of Microbiology at University of Food Technologies, Plovdiv, Bulgaria.

\section{Milk}

Fresh, homogenized and pasteurized cow's milk with $\mathrm{pH} 6.7$ and titratable acidity of $16.5^{\circ} \mathrm{T}$ was used. The milk was delivered by BCC Handel Ltd., town of Elena, Bulgaria.

\section{Methods}

\section{Preparation of spore suspension}

The test fungus Penicillium sp. was grown on MEA at $30^{\circ} \mathrm{C}$ for 7 days or until sporulation. The inoculum was prepared by addition of $5 \mathrm{~mL}$ of sterile $0.5 \% \mathrm{NaC}$ into the tube. After vigorous shaking the inoculum was filtered and replaced in another tube before use. The number of fungal spores was determined using a Thoma's haemocytometer. Final spore concentration in the inoculum was adjusted to $1.6 \times 10^{7} \mathrm{cfu} / \mathrm{mL}$ then a working dilution with spore concentration of $1.6 \times 10^{5}$ $\mathrm{cfu} / \mathrm{mL}$ was prepared.

Minimal inhibitory concentration (MIC) of purified bacteriocin (PB) and determination of the arbitrary units $(A U)$

MIC of the purified bacteriocin of B. methylotrophicus BM47 was determined by the conventional method according to Tumbarski et al. (2017). Series of two-fold dilutions of the bacteriocin ranging from 10.0 to $0.079 \mathrm{mg} / \mathrm{mL}$ were prepared Duplicate samples of each dilution were pipetted in quantity of $60 \mu \mathrm{L}$ into wells cut in a preliminarily inoculated with the test microorganism LBG-agar medium. The Petri dishes were incubated at $30^{\circ} \mathrm{C}$ for $48 \mathrm{~h}$. The MIC value was determined as the lowest concentration of $\mathrm{PB}$ inhibiting completely the growth of the test microorganism around the agar well. The calculation of arbitrary units (AU) for application in milk was based on the obtained MIC value.

\section{Experimental procedure}

The traditional Bulgarian yogurt was prepared in our laboratory according to the Bulgarian State Standard (BSS 12:2010). The homogenized and pasteurized raw cow's milk was heated at $45-46^{\circ} \mathrm{C}$ and transferred in quantity of $100 \mathrm{~mL}$ into sterile plastic cups with lids. Then $1 \%$ of fresh symbiotic starter culture MZ2 $\left(1.0 \times 10^{8}\right.$ $\mathrm{cfu} / \mathrm{mL}$ ) was added to the cups and mixed. The cups were separated in four groups - the first group was kept as a control; the second group was treated with PB (1 $\mathrm{AU} / \mathrm{mL}$ ); the third group was inoculated with spore suspension of Penicillium $\mathrm{sp}$. providing around $2.5 \times 10^{2}-5.0 \times 10^{2} \mathrm{cfu} / \mathrm{mL}$ of milk; the fourth group was treated with PB and inoculated with spore suspension of Penicillium sp. (in the same amounts). For each day of the testing (1-st, 7-th, 14-th, 21-st and 28-th) separate samples were provided. All milk samples were incubated at $44^{\circ} \mathrm{C} \pm 2{ }^{\circ} \mathrm{C}$ for $2.5-$ $3.5 \mathrm{~h}$. After coagulation, all samples were cooled and stored at $4^{\circ} \mathrm{C}$. The morphological, biochemical and microbiological changes as well as the antifungal effect of PB in yogurt were monitored once a week, for 4 weeks.

\section{Enumeration of characteristic microorganisms}

Colony-count technique for lactobacilli and lactic streptococci was implemented on MRS-agar and M17-agar respectively, at $37^{\circ} \mathrm{C}$ according to the Bulgarian State Standard BSS ISO 7889:2005.

\section{Enumeration of yeasts and/or fungi in milk}

Colony-count technique for yeasts and/or fungi in milk was implemented on CGA at $25^{\circ} \mathrm{C}$ according to the Bulgarian State Standard BSS ISO 6611:2006.

\section{Determination of titratable acidity}

Determination of titratable acidity was implemented according to the Bulgarian State Standard BSS 1111:1980. The titratable acidity was determined by titration of each sample with $0.1 \mathrm{~N} \mathrm{NaOH}$ using phenolphthalein as an indicator until the appearance of a pale pink colour persisting over $1 \mathrm{~min}$. One Torner degree $\left({ }^{\circ} \mathrm{T}\right)$ corresponds to $1 \mathrm{~mL}$ of $0.1 \mathrm{~N} \mathrm{NaOH}$, needed for neutralisation of an equivalent amount of organic acid, contained in $100 \mathrm{~mL}$ of milk. The results were calculated as mean value of three consecutive experiments.

\section{RESULTS AND DISCUSSION}

After estimation of MIC of PB of B. methylotrophicus BM47 against the indicator microorganism Penicillium sp. $(2.5 \mathrm{mg} / \mathrm{mL})$, the arbitrary units (AU) for application in milk were calculated to the amount of $\mathrm{PB}$ in $60 \mu \mathrm{L}(0.15 \mathrm{mg})$ and this dose was accepted as equivalent to $100 \mathrm{AU}$. To provide the desirable concentration of $1 \mathrm{AU} / \mathrm{mL}$, in the experimental procedure $0.15 \mathrm{mg}$ of $\mathrm{PB}$ was added in $100 \mathrm{~mL}$ of milk.

During the 4-week period of storage under refrigeration conditions $\left(4^{\circ} \mathrm{C}\right)$, the microbiological parameters - number and ratio of lactic acid bacteria - LAB (Lactobacillus bulgaricus and Streptococcus thermophilus), presence of yeasts and fungi, as well as the titratable acidity of four samples - control, yogurt with addition of bacteriocin (sample 1), yogurt inoculated with Penicillium sp. (sample 2) and yogurt with addition of bacteriocin and Penicillium sp. (sample 3) were monitored. The antifungal effect of the purified bacteriocin on the test microorganism Penicillium $\mathrm{sp}$. in the artificially contaminated samples also was observed. The results are summarized in Table 1.

As seen from the results presented in Table 1, during the first day of storage, the titratable acidity values and microbiological parameters of all yogurt samples were in compliance with the BSS 12:2010. The bacteriocin did not inhibit the indicator microorganism Penicillium sp. in yogurt with addition of PB (sample 3) and it concentration was equal $\left(2.3 \times 10^{2} \mathrm{cfu} / \mathrm{g}\right)$ to the yogurt without PB (sample 2). Experimental results obtained on the 7 -th day of monitoring period showed that Lactobacillus bulgaricus and Streptococcus thermophilus retained a high concentration of viable cells, indicating that bacteriocin did not inhibit LAB and did not affect their normal ratio (1:5), which was relatively constant until the end 
of the second week. The titratable acidity of all samples increased slightly, except a control sample in which the increase in acidic degrees was most pronounced. A weak inhibition of the test microorganism Penicillium sp. in the yogurt with addition of bacteriocin (sample 3 ) was observed.

On the 14-th and 21-st days of observation period, an insignificant decrease of the viable lactobacilli and streptococci in the control yogurt sample and bacteriocintreated sample (sample 1) was detected, which maintained a relatively high concentration of viable cells and stable ratio (1:5 - 1:6). Experimental data showed that the titratable acidity of the control yogurt sample reached $130^{\circ} \mathrm{T}$ on the 21 -s day, while the acidity of sample with addition of bacteriocin (sample 1) remained relatively low $-110.8^{\circ} \mathrm{T}$. It was found that bacteriocin of $B$. methylotrophicus BM47 inhibited effectively the indicator fungus Penicillium sp. and significantly reduced its concentration from $3.7 \times 10^{2} \mathrm{cfu} / \mathrm{g}$ (sample 2) to $10 \mathrm{cfu} / \mathrm{g}$ in the yogurt treated with bacteriocin (sample 3) (Fig. 1).

The results of the microbiological analyses demonstrated on the 28-th day of storage, the number of LAB decreased with 2-3 log units and their ratio changed to 1:7 with a prevalence of $S$. thermophilus due to the faster death of Lb. bulgaricus cells in the end of storage of fermented milk products. Titratable acidity of all samples at the end of monitoring period reached values between $130^{\circ} \mathrm{T}$ and $134.6^{\circ} \mathrm{T}$, which was in the allowable limit of $150^{\circ} \mathrm{T}$ according to the BSS $12: 2010$ The same trend of effective inhibition of the test fungus Penicillium sp. in the yogurt with bacteriocin (sample 3) was observed

Table 1 Effect of PB of B. methylotrophicus BM47 on some microbiological and physicochemical parameters of Bulgarian yogurt

\begin{tabular}{|c|c|c|c|c|c|}
\hline \multirow{3}{*}{ Day } & \multirow{3}{*}{ Parameter } & \multicolumn{4}{|c|}{ Samples } \\
\hline & & \multirow[b]{2}{*}{ Yogurt (control) } & 1 & 2 & 3 \\
\hline & & & Yogurt + PB & $\begin{array}{c}\text { Yogurt + } \\
\text { Penicillium sp. }\end{array}$ & $\begin{array}{l}\text { Yogurt + PB + } \\
\text { Penicillium sp. }\end{array}$ \\
\hline \multirow{5}{*}{1} & LB $(\mathrm{cfu} / \mathrm{g})$ & $1.0 \times 10^{8}$ & $1.0 \times 10^{8}$ & n. a. & n. a. \\
\hline & ST (cfu/g) & $5.0 \times 10^{8}$ & $5.0 \times 10^{8}$ & n. a. & n. a. \\
\hline & Yeasts (cfu/g) & $<10$ & $<10$ & $<10$ & $<10$ \\
\hline & Fungi (cfu/g) & $<10$ & $<10$ & $2.3 \times 10^{2}$ & $2.3 \times 10^{2}$ \\
\hline & $\mathbf{T A}\left({ }^{\circ} \mathrm{T}\right)$ & $90.6 \pm 0.04 *$ & $90.6 \pm 0.04$ & $90.6 \pm 0.04$ & $90.6 \pm 0.04$ \\
\hline \multirow{5}{*}{7} & LB (cfu/g) & $9.0 \times 10^{7}$ & $6.6 \times 10^{7}$ & n. a. & n. a. \\
\hline & ST (cfu/g) & $4.5 \times 10^{8}$ & $3.3 \times 10^{8}$ & n. a. & n. a. \\
\hline & Yeasts (cfu/g) & $<10$ & $<10$ & $<10$ & $<10$ \\
\hline & Fungi (cfu/g) & $<10$ & $<10$ & $2.5 \times 10^{2}$ & $1.5 \times 10^{2}$ \\
\hline & TA $\left({ }^{\circ} \mathrm{T}\right)$ & $99.9 \pm 0.05$ & $92.2 \pm 0.06$ & $94.1 \pm 0.06$ & $93.4 \pm 0.05$ \\
\hline \multirow{5}{*}{14} & LB (cfu/g) & $4.0 \times 10^{7}$ & $3.0 \times 10^{7}$ & n. a. & n. a. \\
\hline & ST (cfu/g) & $2.0 \times 10^{8}$ & $1.5 \times 10^{8}$ & n. a. & n. a. \\
\hline & Yeasts (cfu/g) & $<10$ & $<10$ & $<10$ & $<10$ \\
\hline & Fungi (cfu/g) & $<10$ & $<10$ & $2.8 \times 10^{2}$ & 60 \\
\hline & TA $\left(^{\circ} \mathrm{T}\right)$ & $129.3 \pm 0.06$ & $106.7 \pm 0.06$ & $110.7 \pm 0.05$ & $108.7 \pm 0.05$ \\
\hline \multirow{5}{*}{21} & LB $(\mathrm{cfu} / \mathrm{g})$ & $2.4 \times 10^{6}$ & $1.7 \times 10^{6}$ & n. a. & n. a. \\
\hline & ST (cfu/g) & $1.5 \times 10^{7}$ & $1.0 \times 10^{7}$ & n. a. & n. a. \\
\hline & Yeasts (cfu/g) & $<10$ & $<10$ & $<10$ & $<10$ \\
\hline & Fungi (cfu/g) & $<10$ & $<10$ & $3.7 \times 10^{2}$ & 10 \\
\hline & TA $\left({ }^{\circ} \mathrm{T}\right)$ & $130.0 \pm 0.1$ & $110.8 \pm 0.1$ & $120.5 \pm 0.1$ & $126.0 \pm 0.1$ \\
\hline \multirow{5}{*}{28} & LB (cfu/g) & $1.5 \times 10^{5}$ & $1.2 \times 10^{5}$ & n. a. & n. a. \\
\hline & ST (cfu/g) & $1.0 \times 10^{6}$ & $1.0 \times 10^{6}$ & n. a. & n. a. \\
\hline & Yeasts $(\mathrm{cfu} / \mathrm{g})$ & $<10$ & $<10$ & $<10$ & $<10$ \\
\hline & Fungi (cfu/g) & $<10$ & $<10$ & $3.7 \times 10^{2}$ & 10 \\
\hline & TA $\left({ }^{\circ} \mathrm{T}\right)$ & $134.6 \pm 0.1$ & $133.3 \pm 0.1$ & $129.7 \pm 0.1$ & $130.0 \pm 0.1$ \\
\hline
\end{tabular}

Legend: PB - purified bacteriocin; LB - Lactobacillus bulgaricus; ST - Streptococcus thermophilus; TA - titratable acidity; n. a. - not applicable; * - \pm SD

- standard deviation $(\mathrm{n}=3)$.

Yeasts and fungi as a side microflora or contamination in all samples until the end of storage period were not detected. It was found that bacteriocin of $B$. methylotrophicus BM47 did not affect the growth of LAB and did not change the organoleptic properties (colour, smell and consistency) of yogurt. Therefore, the results of this study revealed the potential possibilities for application of bacteriocin of $B$. methylotrophicus BM47 as an agent for a biopreservation of Bulgarian yogurt

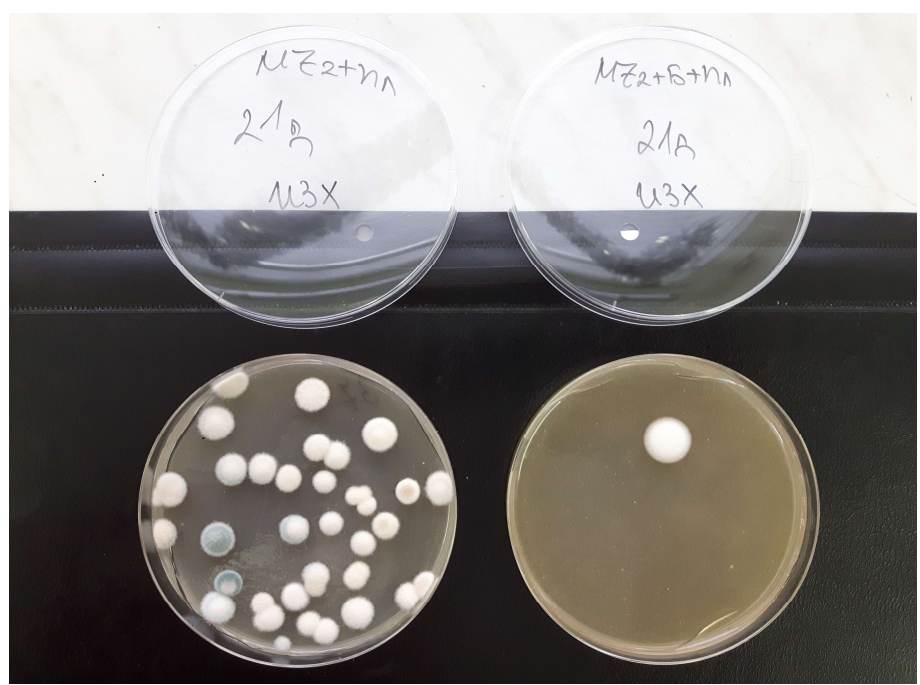

Figure 1 Antifungal effect of the PB of B. methylotrophicus BM47 in yogurt on the 21-st day of storage - sample inoculated with Penicillium sp. (left); sample inoculated with Penicillium sp. and addition of $\mathrm{PB}$ in dose $1 \mathrm{AU} / \mathrm{mL}$ (right)
The significant antifungal activity of the bacteriocin of B. methylotrophicus BM47 was demonstrated in our previous study, in which besides on Penicillium sp. this bacteriocin showed inhibitory effect on fungi from the genera Aspergillus sp. and Fusarium sp. with the same values of MIC $-2.5 \mathrm{mg} / \mathrm{mL}$, and revealed promising potential as biopreservative of raw cow's milk (Tumbarski et al., 2018).

Filamentous fungi are among the main spoilage microorganisms of different stored foods such as fermented dairy products (cheese and yogurt), bread, stored crops and animal food. Presently, the contamination of food with various fungal species is a serious problem due to three main reasons: a) alteration of the texture profile and external aspect of affected products; b) production of mycotoxins, conidia mycelia and spores during fungal growth, which is related to some health risks such as allergic conditions; c) significant economic loses for the food industry. These problems could be overcome by adoption of different advanced approaches that prevent the growth of spoilage microorganisms and extend the shelf-life of milk products. The shelf-life of various cultured milk products could be enhanced by application of a single or a combination of the following biopreservation techniques: a) use of suitable starter cultures containing lactobacilli with proven antifungal activity - Lactobacillus rhamnosus, Lactobacillus fermentum, Lactobacillus acidophilus, Lactobacillus plantarum, Lactobacillus coryniformis subsp. coryniformis, Lactobacillus sanfrancisensis, Lactobacillus casei, Lactobacillus delbrueckii subsp. bulgaricus, Lactobacillus lactis subsp. cremoris (Tropcheva et al., 2014b; Salas et al., 2017); b) application of natural antimicrobial compounds such as bacteriocins (nisin) or bacteriocin-like substances (BLIS) from various bacterial species/strains (MicrogardTM, Lacticin 3147, Leucocin F10 and pediocin $\mathrm{AcH}$ ); c) use of non-toxic and generally recognised as safe (GRAS) antifungal antibiotics obtained from differen microorganisms such as Natamycin from Streptomyces natelensis (Sarkar, 2006; Hasan et al., 2008).

Some recent studies concerning the bioprotection of food described the possibilities for application of bacteriocins against different spoilage microorganisms and their effectiveness as biopreservatives of yogurt. Misirlilar $\boldsymbol{e}$ 
al. (2012) reported the inhibitory effect of nisin (produced by Lactococcus lactis subsp. lactis) on undesirable yeasts and fungi, and its application as GRAS agent for extension of shelf-life without changes of the sensory properties of yogurt. The application of nisin against spoilage microorganisms in fermented dairy products is exploited also by other authors. Gupta and Prasad (1989) found that nisin at a concentration of $25 \mathrm{RU} / \mathrm{g}$ enhanced the shelf-life of stirred yogurt from 5-10 days at $7^{\circ} \mathrm{C}$ without significant change in its sensory properties such as flavor, body, texture and consistency. Nisin and nisin producing microorganisms were also found effective in biopreservation of dahi (traditional fermented milk product typical for South Asian countries) during storage at $25^{\circ} \mathrm{C}$ (Rajmohan and Prasad, 1995) and addition of nisin in dahi at a dose of $15 \mathrm{RU} / \mathrm{g}$ retained all its desirable characteristics up to 35 days at $15 \pm 1^{\circ} \mathrm{C}$ (Kumar et al., 1998).

\section{CONCLUSION}

This is the first report performing the application of a bacteriocin synthesized by B. methylotrophicus BM47 as an antifungal agent in biopreservation of traditional Bulgarian yogurt. The addition of bacteriocin in milk for production of yogurt led to effective inhibition and reduction of the number of test microorganism Penicillium sp. in experimentally contaminated yogurt samples during four weeks of storage at $4^{\circ} \mathrm{C}$, without alteration of their organoleptic characteristics. Therefore, the bacteriocin isolated from B. methylotrophicus BM47 could be considered as a potential agent for biopreservation of Bulgarian yogurt and suitable for application in the dairy industry against spoilage microorganisms of funga origin.

Acknowledgements: This work was financed by Fund „Science“ of University of Food Technologies, Plovdiv, Bulgaria (Grant 06/16-H).

The authors declare that no conflict of interest exists.

\section{REFERENCES}

Ahmed, A. H., Moustafa, M., El-Bassiony, T. A. (1986). Growth and survival of Yersinia enterocolitica in yogurt. Journal of Food Protection, 49, 983-985.

Álvarez-Ordóñez, A., Valdés, L., Bernardo, A., Prieto, M., López M. (2013). Survival of acid adapted and non-acid adapted Salmonella typhimurium in pasteurized orange juice and yogurt under different storage temperatures. Food Science and Technology International, 19(5), 407-414. https://doi.org/10.1177/1082013212455343

Bachrouri, M., Quinto, E. J., Mora M. T. (2002). Survival of Escherichia coli O157:H7 During Storage of Yogurt at Different Temperatures. Journal of Food Science, 67(5), 1899-1903. https://doi.org/10.1111/j.1365-2621.2002.tb08743.x

Benkerroum, N., Oubel, H., Mimoun, L. B. (2002). Behavior of Listeria monocytogenes and Staphylococcus aureus in Yogurt Fermented with a Bacteriocin-Producing Thermophilic Starter. Journal of Food Protection, 65(5), 799-805.

Beshkova, D., Simova, E., Frengova, G., Simov, Z. (1998). Production of flavour compounds by yogurt starter cultures. Journal of Industrial Microbiology and Biotechnology, 20, 180-186. https://doi.org/10.1038/sj.jim.2900504

Bulgarian State Standard BSS ISO 7889:2005. Yogurt - Enumeration of characteristic microorganisms - Colony-count technique at 37 degrees $\mathrm{C}$.

Bulgarian State Standard BSS 12:2010. Bulgarian Yogurt.

Bulgarian State Standard BSS ISO 6611:2006. Milk and milk products Enumeration of colony-forming units of yeasts and/or moulds - Colony-coun technique at 25 degrees $C$.

Bulgarian State Standard BSS 1111:1980. Milk and milk products - Determination of acidity.

Cholakov, R., Tumbarski, Y., Yanakieva, V., Dobrev, I., Salim, Y., Denkova, Z (2017). Antimicrobial activity of Leuconostoc lactis strain $\mathrm{BT}_{1} 7$, isolated from a spontaneously fermented cereal beverage (boza). Journal of microbiology, biotechnology and food sciences, 7(1), 47- 49 http://doi.org/10.15414/jmbfs.2017.7.1.47-49

Falenski, A., Mayer-Scholl, A., Filter, M., Göllner, C., Appel, B., Nöckler, K (2010). Survival of Brucella spp. in mineral water, milk and yogurt. International Journal of Food Microbiology, 145(1), 326-330 https://doi.org/10.1016/j.ijfoodmicro.2010.11.033

Fikiin, K. A., Fikiin A. G., Russell, S. L., Fitt, P.W. (1997). Shelf-life extension of Bulgarian yoghurt by using a novel environment-friendly aircycle integrated system for thermal and refrigerated processing. In: Shelf-Life Prediction for Improved Safety and Quality of Foods -Proceedings of EU COPERNICUS Workshop, Project CIPA-CT94-0120, Wageningen (The Netherlands), 159-168. https://doi.org/10.13140/RG.2.1.5152.9447/1

Fisberg, M., Machado, R. (2015). History of yogurt and current patterns of consumption. Nutrition Reviews, 73(S1), 4-7.

https://doi.org/10.1093/nutrit/nuv020

Gupta, R. K., Prasad, D. N. (1989). Incorporation of nisin in stirred yoghurt. II. Effect on biochemical activities during storage. Cultured Dairy Products Journal, 24, 9-10.

Hasan, T., Eroglu, E., Soyer, F., Ozen, B. (2008). Antifungal activity of biopolymers containing natamycin and rosemary extract against Aspergillus niger and Penicillium roquefortii. International Journal of Food Science and Technology, 43, 2026-2032. https://doi.org/10.1111/i.1365-2621.2008.01816.x

Ikonomov, L., Todorov, D. (1967). Microbiological studies on the pasteurization of ewes' milk. III: Resistance of some pathogenic bacteria. Vet. Med. Nauki, Sof. 4, 99-108. (Dairy Sci. Abstr. 27(2), 82.

Kumar, R., Sarkar, S. and Misra, A.K. (1998). Effect of nisin on the quality of dahi. Journal of Dairying Food and Home Sciences, 17, 13-16.

McKinley, M. C. (2005). The nutrition and health benefits of yoghurt International Journal of Dairy Technology, 58(1), 1-12 https://doi.org/10.1111/j.1471-0307.2005.00180.x

Misirlilar, F., Kinik, Ö., Yerlikaya, O. (2012). Effect of protective culture and biopreservatives on strained yoghurt quality. African Journal of Microbiology Research, 6(22), 4696-4701. https://doi.org/10.5897/AJMR11.1319

Pazakova, J., Turek, P., Laciakova, A. (1997). The survival of Staphylococcus aureus during the fermentation and storage of yoghurt. Journal of Applied Microbiology, 82(5), 659-662. https://doi.org/10.1111/j.1365 2672.1997.tb03599.x

Pitt, J. I., Hocking, A. D. (2009). Fungi and food spoilage. Third edition. Springer, ISBN 978-0-387-92207-2.

Quigley, L., O’Sullivan, O., Stanton, C., Beresford, T. P., Ross, R. P., Fitzgerald, G. F., Cotter, P. D. (2013). The complex microbiota of raw milk. FEMS Microbiology Reviews, 37, 664-698. https://doi.org/10.1111/1574-6976.12030

Rajmohan, S., Prasad, V. (1995). Effect of nisin on the chemical changes in dahi. Indian Journal of Dairy Science, 48, 633

Salas, M. L., Mounier, J., Valence, F., Coton, M., Thierry, A., Coton E. (2017) Antifungal Microbial Agents for Food Biopreservation - A Review. Microorganisms, 5(3), 37. https://doi.org/10.3390/microorganisms5030037

Sarkar, S. (2006). Shelf-life extension of cultured milk products. Nutrition and Food Science, 36(1), 24-31.

https://doi.org/10.1108/00346650610642160

Schaack, M. M., Marth E. H. (1988). Behavior of Listeria monocytogenes in Skim Milk and in Yogurt Mix during Fermentation by Thermophilic Lactic Acid Bacteria. Journal of Food Protection, 51(8), 607-614.

Tropcheva, R., Georgieva, R., Paskov, V., Karsheva, M., Danova, S. (2014a) Sensory properties of Bulgarian yogurts, supplemented with lactobacilli as probiotic adjuncts. Journal of Texture Studies, 45(3), 187-194 https://doi.org/10.1111/jtxs.12065

Tropcheva, R., Nikolova, D., Evstatieva, Y., Danova S. (2014b). Antifungal activity and identification of Lactobacilli, isolated from traditional dairy product "katak". Anaerobe, 28, 78-84. http://dx.doi.org/10.1016/j.anaerobe.2014.05.010

Tumbarski, Y., Lincheva, V., Petkova, N., Nikolova, R., Vrancheva, R., Ivanov I. (2017). Antimicrobial activity of extract from aerial parts of potentilla (Potentilla reptans L.). Industrial Technologies, 4(1), 37-43.

Tumbarski, Y., Yanakieva, V., Nikolova, R., Mineva, G., Deseva, I., Mihaylova D., Ivanov I. (2018). Application of a bacteriocin isolated from Bacillus methylotrophicus BM47 as a biopreservative in raw cow's milk. Industrial Technologies, vol. 5(1), in press. 